\title{
Study on the Path of Rural Ecological Civilization Construction Based on Multi-cooperative Governance from the Perspective of Rural Revitalization
}

\author{
Xiao Li \\ Heilongjiang Bayi Agricultural University, Heilongjiang, 163319, China \\ lixiao800828@163.com
}

Keywords: Rural Revitalization, Ecological civilization, a moderately prosperous society, Multiple subjector.

\begin{abstract}
Rural revitalization strategy is the basis of promoting the comprehensive construction of a well-off society. It aims to achieve the harmonious coexistence between man and nature and realize the green development of rural areas by creating a new ecological and livable rural development model. Implementing the rural revitalization strategy is an important deployment to promote the construction of socialist ecological civilization, and ecological revitalization is the key to implementing the rural revitalization strategy. To effectively integrate the construction of ecological civilization into all aspects and the whole process of economic construction, we need to deal with the cooperative governance relationship among government, market, social organizations and the public. At present, the requirements of rural ecological civilization construction in China are well known, but the forces that hinder and destroy the construction of rural ecological civilization still exist. Based on the perspective of multiple cooperative governance, this paper discusses the value status and path selection of rural ecological revitalization in the implementation of Rural Revitalization Strategy, so as to realize the win-win strategy of multiple subjects, and construct the multi subject collaborative governance to promote the construction of ecological civilization in China.
\end{abstract}

\section{Introduction}

Ecological environment is an important foundation of economic and social development, and the quality of ecological environment is directly related to human survival and health. The report of the 18th National Congress of the Communist Party of China clearly pointed out that the construction of ecological civilization is a long-term plan related to the well-being of the people and the future of the nation [1]. The ecological environment problem in contemporary China is no longer a local and temporary problem, but a holistic, global and long-term problem [2]. Facing the severe situation of resource constraints, serious environmental pollution and ecosystem degradation, we must establish the concept of ecological civilization of respecting nature, conforming to nature and protecting nature, and put the construction of ecological civilization in a prominent position [3]. The construction of rural ecological civilization "is conducive to promoting the sustainable development of rural 
ecological environment and economic society, is a strong support for the realization of rural ecological civilization, and is an important part of the construction of rural ecological civilization" [4]. However, at present, each subject in the construction of ecological civilization in China tends to be fragmented. Most of the time, they fight alone and do not form a joint force to build from the overall situation and the whole, which often leads to the failure of many work in the construction of ecological civilization [5]. Good ecological environment is the key to the implementation of Rural Revitalization Strategy, and the implementation of Rural Revitalization is essentially the process of continuously improving the rural ecological environment. Based on the background of the new era of socialist ecological civilization construction.

Under the conditions of the new era, the combination of ecological civilization construction and Rural Revitalization Strategy, while promoting rural revitalization, does not forget the construction of ecological civilization, is conducive to building a socialist modern power [6]. The construction of rural ecological civilization is a necessary condition for the development of rural modernization. China has a large proportion of rural population and a wide distribution of rural areas. The success of rural ecological civilization construction is related to the achievements of China's overall ecological civilization construction [7]. In the new era, the inevitable choice to promote the construction of ecological civilization is to actively build a multi subject collaborative governance in the construction of ecological civilization and realize the multi subject cooperation in the construction of ecological civilization [8]. Starting from the analysis of the relationship between the Rural Revitalization Strategy and the construction of rural ecological civilization, this paper puts forward some effective suggestions on the construction of rural ecological civilization in China by thinking about the prominent problems and severe challenges faced by the construction of rural ecological civilization in China. Only in accordance with the requirements of the scientific outlook on development, establishing a sense of regional community of overall planning and coordination, through in-depth system and mechanism innovation, establishing a multi linkage mechanism of cross regional ecological cooperation and governance, and taking multi linkage action of cross regional ecological cooperation and governance, can China's ecological civilization construction achieve continuous results.

\section{The internal relationship between Rural Revitalization and rural ecological civilization}

The development of agriculture is the most fundamental embodiment of the construction of rural ecological civilization. The development of agriculture is excellent and the development of rural economy has been promoted. This forms a strong guarantee for the construction of rural ecological civilization, and rural revitalization requires the creation of a beautiful countryside with "prosperous industry, ecological livability, civilized rural customs, effective governance and affluent life", which embodies the rural residents' pursuit of spiritual and material life. Rural revitalization strategy is an important strategy which takes the integration of urban and rural development as the main content and the pattern of urban and rural integration development, improves the rural basic economic system, promotes the linkage development of the three major industries in rural areas, improves the status quo of rural development lagging behind for a long time, and achieves the goal of rural sustainable development. Rural sustainable prosperity requires the establishment of a powerful long-term policy mechanism to ensure rural sustainable prosperity, so as to ensure that rural people are getting richer and more beautiful on the road to a new socialist countryside. Rural civilization highlights the importance of rural ecological civilization construction and is an important influencing factor of beautiful countryside [9]. Effective governance is the fundamental requirement of rural ecological civilization construction, and affluent life is the source of people's happiness. Effective governance and rural civilization provide realistic conditions for realizing ecological livability, which is not only 
the concrete implementation of rural revitalization strategy, but also the practical realization of the goal of "people's longing for a better life". Ecological civilization is the basic mountain of respecting and adapting to nature in ethical cognition, aiming at the harmonious development of man and nature. Ancient ecological civilization is the unity of man and nature, which emphasizes the integration of man and nature. The rural tourism transportation solution based on cloud Internet architecture is shown in Figure 1.

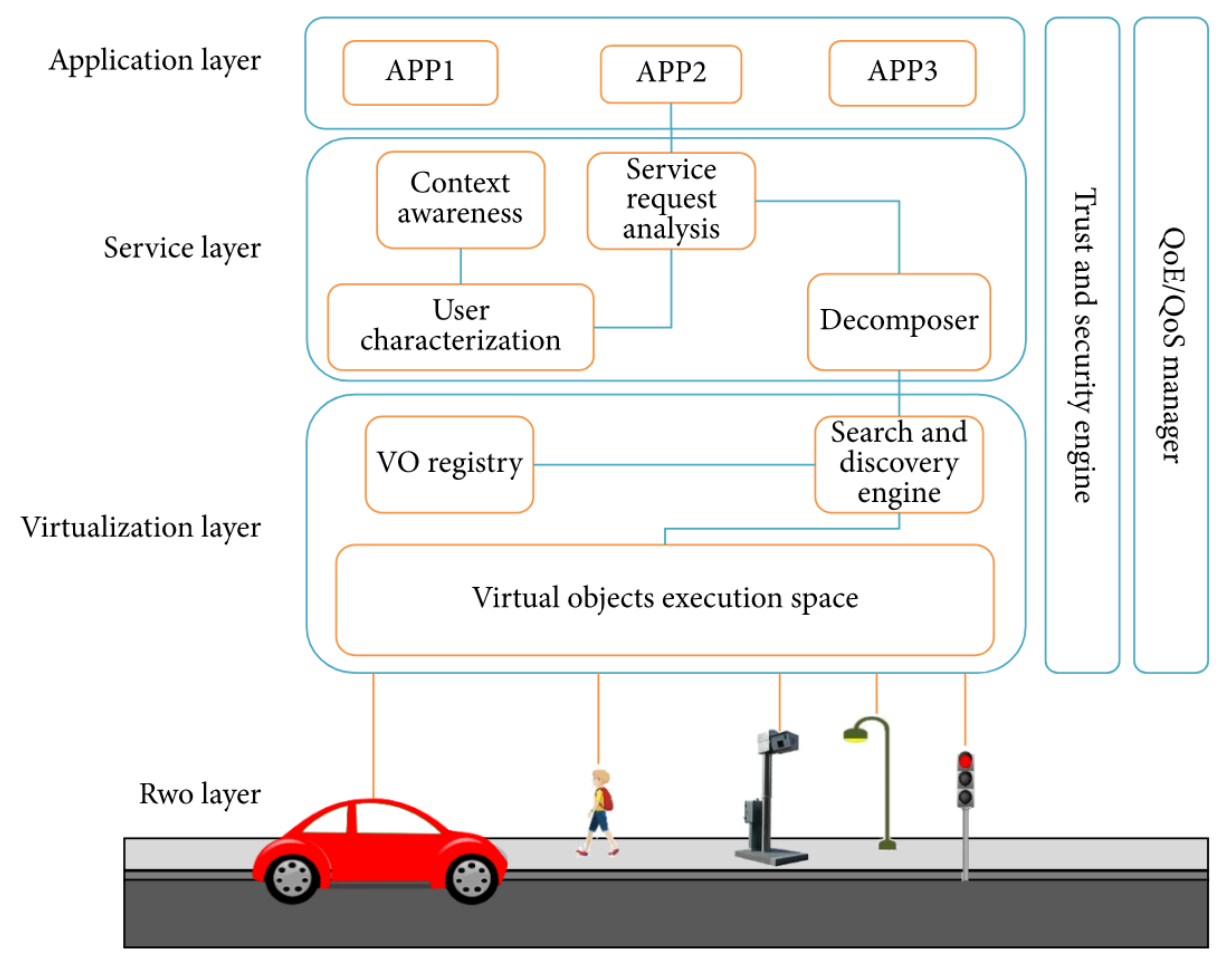

Figure 1: Traffic solutions based on cloud Internet architecture

Ecological civilization is not only reflected in promoting the balance and self-repair of ecological system, creating a beautiful picture of harmonious coexistence between man and nature, and sustainable development of resources and environment, but also in changing human thinking mode and guiding people to establish ecological consciousness, environmental protection consciousness and green consciousness, so as to build a fair, just, green, ecological and harmonious new civilization mode shared by all mankind. Rural ecological civilization construction leads rural revitalization. In the whole process of rural ecological civilization construction, overall planning, rational layout and improvement of rural living environment should be promoted according to local conditions. Rural ecological civilization construction is to put ecological environment protection in the first place, put ecological civilization construction ahead of economic construction, take the restoration and protection of ecological environment as the primary goal, and promote the construction of rural ecological civilization and the development of ecological culture. In farmers' production practice, they will handle the relationship between man and nature well, consciously protect the ecological environment and respect and reflect the ecological value of the environment. Rural ecological civilization construction is a powerful driver of rural revitalization while leading rural revitalization. Rural revitalization strategy provides normative constraints and theoretical guidance for rural production civilization construction. Rural people have the closest relationship with nature, and are the forefront of ecological environment protection. The construction of rural ecological civilization faces many problems and heavy tasks, and the degree of construction is directly related to the 
implementation process of rural revitalization strategy. Therefore, in rural areas, ecological environment protection must be placed in a prominent position, environmental pollution control should be strengthened, and the harmonious coexistence between man and nature and the construction of beautiful countryside should be the main development goals. China's rural economy is gradually transforming from the original extensive resource consumption type to the large-scale economy of scientific and technological innovation, so that the rural economy will transform into an ecological economy and advocate an environmentally friendly, green and low-carbon way. However, the construction of rural ecological civilization is to transform rural development into ecological economy, which will provide strong support for rural revitalization.

\section{Path selection of rural ecological civilization construction from the perspective of Rural Revitalization Strategy}

\subsection{Improve the system}

The strategy of Rural Revitalization provides theoretical guidance for the construction of rural ecological civilization in China. The establishment of a perfect system will help the construction of rural ecological civilization in China to develop healthily, stably and continuously, and provide theoretical guidance and legal guarantee for the further improvement of the relevant system system. In the construction of rural ecological agriculture, we must choose the appropriate ecological agriculture mode according to the terrain and soil fertility, and at the same time, industry feeds agriculture back to form a benign circular development between industry and agriculture and urban and rural areas. The perfect system is the premise and foundation of rural ecological civilization construction. The final implementation of rural strategy is rural. All regions should formulate the system in line with the local development needs according to the local actual situation, so as to ensure the smooth progress of rural ecological civilization construction. In the construction of ecological civilization, only by changing the government function, giving full play to the role of each subject and making each subject participate equally can we effectively promote the construction of ecological civilization.

\subsection{Strengthen the improvement of supporting infrastructure}

In the new era, rural development planning should take ecological livability as the foothold. In the process of planning and building beautiful countryside, the source protection system should be formulated. For the pollution and damage to the environment, the damage compensation and punishment system should be formulated to avoid the pollution and damage in a vicious circle again. The corresponding evaluation and supervision system should also be formulated to effectively control the ecological damage. The government needs to transform from the all-round government role of over-managing, over-careful and over-dying, and become a guide to guide other subjects to actively participate in shouldering their due responsibilities. The ecological environment is public, and the advantages and disadvantages of the environment are related to everyone's interests. It can be said that the construction of ecological civilization is everyone's duty, which requires not only the government's contribution, but also others' contribution. The construction of rural ecological civilization should first take the people as the core, adhere to the people-oriented principle, and at the same time respect and avoid violating the laws of nature. Rural infrastructure construction should conform to the nature, rationally plan the layout, not destroy the village space, and rectify the unreasonable layout of existing villages. Rural people, as rural subjects, play an irreplaceable role in realizing rural ecological civilization. Therefore, strengthening rural people's ecological civilization ideological construction and improving rural people's awareness of ecological construction protection 
are conducive to enhancing their sense of identity of rural subjects, stimulating their sense of responsibility for rural ecological civilization construction, and self-restraining all behaviors that do not meet the requirements of ecological civilization construction, thus providing the main force for rural ecological civilization construction.

\section{Conclusions}

Ecological environment is an important foundation of economic and social development, and its quality is directly related to human survival and health. Agriculture is the foundation of national economy, and the stability of agricultural production is related to national stability. Rural economic development is not only the source guarantee of rural ecological civilization construction, but also the internal motive force of rural revitalization. To promote the construction of rural ecological civilization is not only to protect the environment and realize sustainable development, but also to realize the harmonious coexistence between man and nature. Rural ecological civilization construction is a systematic project. Although China's rural ecological civilization has made some progress, there are still many problems such as insufficient investment in capital and technology, and there is still a long way to go in rural ecological civilization construction. Multi-subjects of ecological civilization are the owners or force representatives of different ecological resources, which form different but irreplaceable roles and functions. Under the strategy of rural revitalization, the construction of rural ecological civilization needs the concerted efforts of the government and the people. Only by forming a harmonious and different governance mode of ecological civilization construction can we effectively promote the early realization of beautiful China.

\section{References}

[1]. Luo Yufang. Research on the path of rural ecological civilization construction from the perspective of rural revitalization strategy [J]. Modern Agricultural Research, 2020, 51(03):59-61.

[2]. Gao Jixi, Sun Qinfang, Zhu Lin. Implement rural revitalization strategy to promote rural ecological civilization construction [J]. Environmental Protection, 2018, 46(7): 11-15.

[3]. Li Yujia, Liu Xiaobing. The status quo and prospect of Beijing's ecological civilization construction under the background of rural revitalization [J]. Agricultural Outlook, 2019, 15(04):116-119.

[4]. Luo Yufang. Research on the Path of Rural Ecological Civilization Construction from the Perspective of Rural Revitalization Strategy [J]. Rural Practical Science and Technology Information, 2020,

[5]. Deng Xiaoling. The construction of ecological civilization is the meaning of China's rural revitalization [J]. People's Forum, 2018, 607(26): 76-77.

[6]. Sun Xing, Chen Yili. Research on rural ecological civilization construction under the background of rural revitalization [J]. Popular Literature and Art, 2020, 479(05): 256-257.

[7]. Qiu Wanbao, Cai Yining. Wetland protection countermeasures under the background of ecological civilization construction system reform [J]. Wetland Science and Management, 2019, 015(003): 37-39.

[8]. Fu Yulin. Research on Ecological Civilization Construction in Bijie Experimental Area from the Perspective of Rural Revitalization [J]. Modern Communication, 2020, 524(06): 241-243.

[9]. Chen Xiaojie. On the coupling relationship between rural revitalization and rural ecological civilization construction [J]. Popular Science (Science Education), 2020, 1212(05): 183-184. 